\title{
American College of Radiology
}

National Cancer Institute

\section{Source}

National Cancer Institute. American College of Radiology. NCI Thesaurus. Code C39314.

An FDA-designated accrediting body that includes radiologists, radiation oncologists and medical physicists. The ACR focuses its activity on making imaging safe, effective and accessible trough its accreditation programs, research, and development of guidelines for quality imaging, and education. 